\title{
The role of socio-demographic determinants in the geo-spatial distribution of newly diagnosed HIV infections in small areas of Catalonia (Spain)
}

Cristina Agusti ${ }^{1,2,3^{*}}$ D, Núria Font-Casaseca ${ }^{4}$, Francesc Belvis ${ }^{5,6,7}$, Mireia Juliàa, ${ }^{5,8}$ Núria Vives $^{2,8}$, Alexandra Montoliu ${ }^{2,7}$, Juan M. Pericàs $5^{5,6,9,10}$, Jordi Casabona ${ }^{1,2,3,11}$ and Joan Benach ${ }^{5,6,12}$

\begin{abstract}
Background: Spatial visualization of HIV surveillance data could improve the planning of programs to address the HIV epidemic. The objectives of the study were to describe the characteristics and the spatial distribution of newly diagnosed HIV infection in Catalonia and to identify factors associated with HIV infection rates.

Methods: Surveillance data from the national registry were presented in the form of descriptive and ring maps and used to study the spatial distribution of new HIV diagnoses in Catalonia (2012-2016) and associated risk factors at the small area level (ABS, acronym for "basic health area" in Catalan). Incident cases were modeled using the following as predictors: type of municipality, prevalence of young men and migrant groups, GBMSM activity indicators, and other variables at the aggregated level.

Results: New HIV diagnoses are heterogeneously distributed across Catalonia. The predictors that proved to be significantly associated with a higher rate of new HIV diagnoses were ABS located in the city of Barcelona (IRR, 2.520; $P<0.001$ ), a higher proportion of men aged 15-44 years (IRR, 1.193; $P=0.003$ ), a higher proportion of GBMSM $(I R R, 1.230 ; P=0.030)$, a higher proportion of men from Western Europe (IRR, 1.281; $P=0.003)$, a higher proportion of men from Latin America (IRR, 1.260; $P=0.003$ ), and a higher number of gay locations (IRR, 2.665; $P<0.001)$. No association was observed between the HIV diagnosis rate and economic deprivation.

Conclusions: Ring maps revealed substantial spatial associations for the rate of new HIV diagnoses. New HIV diagnoses are concentrated in ABS located in urban areas. Our results show that, in the case of HIV infection, the socioeconomic deprivation index on which the Catalan government bases its budget allocation policies among the ABS should not be the only criterion used.
\end{abstract}

Keywords: HIV, Small areas, Income inequality, Neighborhood environment

\footnotetext{
* Correspondence: cagusti@iconcologia.net

${ }^{1}$ Centre d'Estudis Epidemiològics sobre les Infeccions de Transmissió Sexual i

Sida de Catalunya (CEEISCAT), Agència de Salut Pública de Catalunya (ASPC),

Generalitat de Catalunya, Edifici Muntanya, Ctra Can Ruti, Cami de les Escoles

s/n, 08916 Badalona, Barcelona, Spain

${ }^{2}$ Centro de Investigación Biomédica en Red de Epidemiologia y Salud

Pública CIBERESP, Madrid, Spain

Full list of author information is available at the end of the article
}

(c) The Author(s). 2020 Open Access This article is licensed under a Creative Commons Attribution 4.0 International License, which permits use, sharing, adaptation, distribution and reproduction in any medium or format, as long as you give appropriate credit to the original author(s) and the source, provide a link to the Creative Commons licence, and indicate if changes were made. The images or other third party material in this article are included in the article's Creative Commons licence, unless indicated otherwise in a credit line to the material. If material is not included in the article's Creative Commons licence and your intended use is not permitted by statutory regulation or exceeds the permitted use, you will need to obtain permission directly from the copyright holder. To view a copy of this licence, visit http://creativecommons.org/licenses/by/4.0/ The Creative Commons Public Domain Dedication waiver (http://creativecommons.org/publicdomain/zero/1.0/) applies to the data made available in this article, unless otherwise stated in a credit line to the data. 


\section{Background}

The World Health Organization recommends that not only should health outcomes, but also their societal distribution and determinants, be taken into account in public health monitoring in order to inform policies, programs, and practices aimed at improving the health of the population and achieving health equity [1]. Knowledge of the spatial incidence of HIV and associated variables can be of interest for the allocation of resources and the design of health policies, as well as for generating theories concerning transmission pathways.

Factors associated with the incidence of HIV infection have proven to be diverse and distributed both worldwide and within countries and transmission groups. Previous studies have revealed statistically significant differences in the distribution of new diagnoses by demographic characteristics and urban setting, with HIV positivity rates being higher in urban areas [2]. On the other hand, rural residents at risk for or living with HIV infection face unique challenges $[2,3]$, namely, they are less likely to have been tested for HIV or have been tested in the past year than urban residents [4].

Population mobility is also a key driver of the HIV epidemic [5] and is linked to a higher incidence of infection [6]. Although attention in recent years has focused on migrants from high-prevalence countries with generalized epidemics, there is evidence that in Europe, specific migrant groups from other regions with more concentrated epidemics, such as gay, bisexual, and other men who have sex with men (GBMSM) from Latin America and Western Europe, are also highly vulnerable to HIV infection [7].

Individual-level adverse health outcomes may be influenced directly or indirectly by the environment where a person lives [8-10]. Gay neighborhoods have been associated with HIV infection [11, 12], although there is some debate over whether living in a gay neighborhood is a risk factor or protective factor. Tieu et al. [9] associated living in a gay neighborhood with safer sex behaviors such as more frequent condom use for receptive and insertive anal sex. This agrees with the fact that individuals who perceive a higher sense of community and neighborhood participation are more likely to report fewer risk behaviors [9]. In contrast, living in a gay neighborhood has been associated with the use of drugs to enhance sexual experiences $[11,13]$.

Studies performed in the United States of America have reported that increased poverty and inequality are associated with the diagnosis of HIV and other sexually transmitted infections [14-16]. In contrast, a study performed in the United Kingdom showed an increased incidence of viral hepatitis and sexually transmitted infections but not HIV infection in deprived areas in the north of England [17]. Buot et al. [18] reported that high income inequality, low income, high unemployment, and high poverty correlate positively with the incidence of HIV. However, the relative importance of these factors differed with the population at risk: rates of infection by heterosexual contact were more significantly associated with income inequality and poverty, whereas GBMSMlinked cases were not significantly associated with socioeconomic indicators [18].

Catalonia, in the northeast of Spain has one of the highest rates of new HIV diagnoses in the country. In 2017, a total of 578 new diagnoses were reported, that is, 8.1 per 100,000 persons [19], which is higher than the European Union median (6.4 cases per 100,000 population) [20]. Men account for $86 \%$ of cases. Half of the diagnoses reported were in GBMSM (54\%). Of these, $47 \%$ were diagnosed in people born outside Spain. More than half $(58 \%)$ of all new diagnoses were made in the city of Barcelona. The median age of the cases was 36 years. Of all new HIV diagnoses in 2017, 38\% were aged $30-39$ years, $29 \%$ were $\geq 40$ years, and $33 \%$ were under 30 years [19]. In Spain, studies on the effect of the geographical and socioeconomic context in the distribution of new HIV diagnoses are lacking.

The objectives of this study were to describe the characteristics and the spatial distribution of new HIV diagnoses in Catalonia using ring maps and to identify factors that are potentially associated with HIV infection rates at the small area level.

\section{Methods}

We performed a cross-sectional ecological study using the "basic health area" (ABS [acronym in Catalan]) as the geographical study unit. The ABS is the regional demarcation used by the Catalan Health Service to organize primary healthcare services. An ABS includes a reference territory of a primary health care team and its population, which comprises 5000-25,000 people. Those ABSs with fewer than 5000 people were merged with bordering $\mathrm{ABSs}$ in order to protect the patient anonymity. During the study period, the limits of the ABSs were sometimes modified (basically ABS splits); this problem was solved by maintaining the original division and aggregating the data. Thus, we obtained a fixed number of 355 ABSs.

\section{New diagnoses of HIV data}

We retrieved data on new HIV diagnoses reported from 2012 to 2016 in the Catalan HIV Surveillance Registry. The Registry is a population-based information system of all persons residing in Catalonia at diagnosis of HIV infection since 2001. The Registry provides the postal code, sex, country of birth, age, and transmission mode.

We calculated five-year aggregated new HIV diagnoses for each ABS. Multiple-year counts provide more stable 
estimates of HIV diagnoses, particularly in ABSs with small populations. New diagnosis rates per 100,000 persons were calculated by dividing the incident case count by the five-year sum of the population assigned yearly to each ABS.

\section{Exposure variables}

To reflect territorial differentiation in Catalonia the ABSs were classified into five categories based on the characteristics of the municipality where each ABS is located, namely, geographical location (Barcelona and its metropolitan area and rest of the territory), population (municipalities with less than 10,000 inhabitants, $10,000-20,000$ and more than 20,000 inhabitants) and population density (inhabitants $/ \mathrm{km}^{2}$ of the municipality or municipalities where the ABS is located). When the ABS included more than one municipality and there was a discrepancy, the municipality of superior rank was prioritized. The five categories were urban Barcelona (ABS in Barcelona city), urban metropolitan (ABS in municipalities included in the metropolitan area of Barcelona), urban county (ABS in municipalities of more than 20,000 inhabitants and outside the metropolitan area of Barcelona), semi-urban (ABS in municipalities with a population of 10,000 and 20,000 inhabitants and a density of more than 150 inhabitants $/ \mathrm{km} 2$, and, rural (ABS in municipalities with fewer than 10,000 inhabitants or a density of less than 150 inhabitants $/ \mathrm{km}^{2}$.

The percentage of men aged 15-44 years among the assigned ABS population (year 2016) and the percentage of men from Western Europe and Latin America (year 2014) at the ABS level were calculated to account for differences in the proportion of men in the most common age range of new HIV diagnoses and the influence of the migrant population, respectively. The percentage for GBMSM as the transmission mode among new HIV diagnoses was calculated by ABS. Given the very small counts in many ABSs, the Agresti-Coull binomial proportion estimation was used to obtain less extreme values; this approach also has the advantage of imputing a value for ABS with zero incidence counts [21]. Relative socioeconomic disadvantage across Catalonia was evaluated using a socioeconomic deprivation index built for the assignation of budgets to the primary healthcare teams in Catalonia [22]. This index is a composite measure based on five indicators extracted from the national health registry of 2015, as follows: percentage of manual workers, percentage of people with a low educational level, rate of premature mortality, rate of avoidable hospitalization, percentage of population exempt from pharmaceutical copayment, and percentage of population with an annual income lower than $€ 18,000$. All these predictor variables were acquired from the set of basic health and health care indicators at the ABS level provided by the Agency of Health Quality and Evaluation of Catalonia (AQuAS) and the Information System for the Development of Research in Primary Care (SIDI $\mathrm{AP})$.

Finally, to identify the gay neighborhoods, all gay locations (eg, bars, discotheques, saunas, hotels, shops, sex clubs, and travel agencies) located in Catalonia were retrieved from the Spartacus Guide and Universo Gay (2018 editions) and later georeferenced to their corresponding ABS. A total of 239 gay locations were mapped.

\section{Spatial visualization methods}

Multivariate ring maps based on Huang et al. and López-De-Fede et al. [15, 23] were constructed. A ring map is a map surrounded by a set of concentric, segmented rings. Each ring displays an additional data dimension that represents an attribute of a particular location. We built maps with a base map of Catalonia in the center showing the rates of new HIV diagnoses for each ABS surrounded by a set of histograms with the distribution of the mode of transmission of HIV, sex, and country of birth for ABSs with new HIV diagnoses rates $>10$ per 100,000 population. The ring maps were developed using QGIS and Inkscape, both are and free open source.

\section{Statistical analysis}

The univariate distribution of the new diagnoses of HIV infection, as well as its association with the predictor variables, was examined from both the statistical and geographical perspective using bivariate statistics.

A negative binomial regression model with the population at risk as an offset was adjusted to account for the overdispersion of new diagnoses of HIV infection. The exponentiated coefficients of the model is the incidence rate ratio (IRR) relative to the reference category. Quantitative variables were scaled to make the IRRs comparable.

The Moran I test was used to check for spatial autocorrelation of the residuals, and a second model including an autocovariate based on the residuals of the first one was fitted. The AIC, BIC, and McFadden's pseudo $\mathrm{R}^{2}$ were calculated to test the quality of the model. All calculations were performed using $\mathrm{R}$.

The study was approved by the Ethics Committee of Hospital Germans Trias i Pujol.

\section{Results}

The characteristics of the new HIV diagnoses reported in Catalonia during the study period (2012-2016) are presented in Table 1.

The choropleths in the base map of Fig. 1 show the rates of new HIV diagnoses. New HIV diagnoses are far 
Table 1 Characteristics of the new HIV diagnoses reported in Catalonia (Spain), 2012-2016. N: 3220

\begin{tabular}{lllll}
\hline & $\mathbf{n}$ & $\%$ & Rate of New HIV Diagnoses $^{\mathbf{a}}$ & 95\%Cl \\
\hline Sex & & & & $(5.75-8.11)$ \\
Male & 2810 & 87.28 & 6.93 & 1.04 \\
Female & 410 & 12.73 & & $(0.90-1.18)$ \\
Country of birth & & 4.76 \\
Spain & 1890 & 58.69 & 3.2 & $(4.23-5.29)$ \\
Other & 1330 & 41.30 & & $(2.42-3.98)$ \\
Transmission mode & & 14.60 & 1.18 & $(1.04-1.32)$ \\
Heterosexual men & 470 & 9.72 & 0.8 & $(0.68-0.92)$ \\
Heterosexual women & 313 & 62.39 & 4.88 & $(3.78-5.98)$ \\
GBMSM & 2009 & 3.79 & 3.69 & $(2.77-4.61)$ \\
PWID & 122 & 9.50 & 0.8 & $(0.68-0.92)$ \\
Other & 306 & 100 & 7.97 & $(6.72-9.22)$ \\
Total & 3220 & &
\end{tabular}

aper 100,000 persons

GBMSM: Gay, bisexual and other men who have sex with men

PWID: People who inject drugs

Other: Parenteral transmission other than PWID, mother to child transmission and unknown

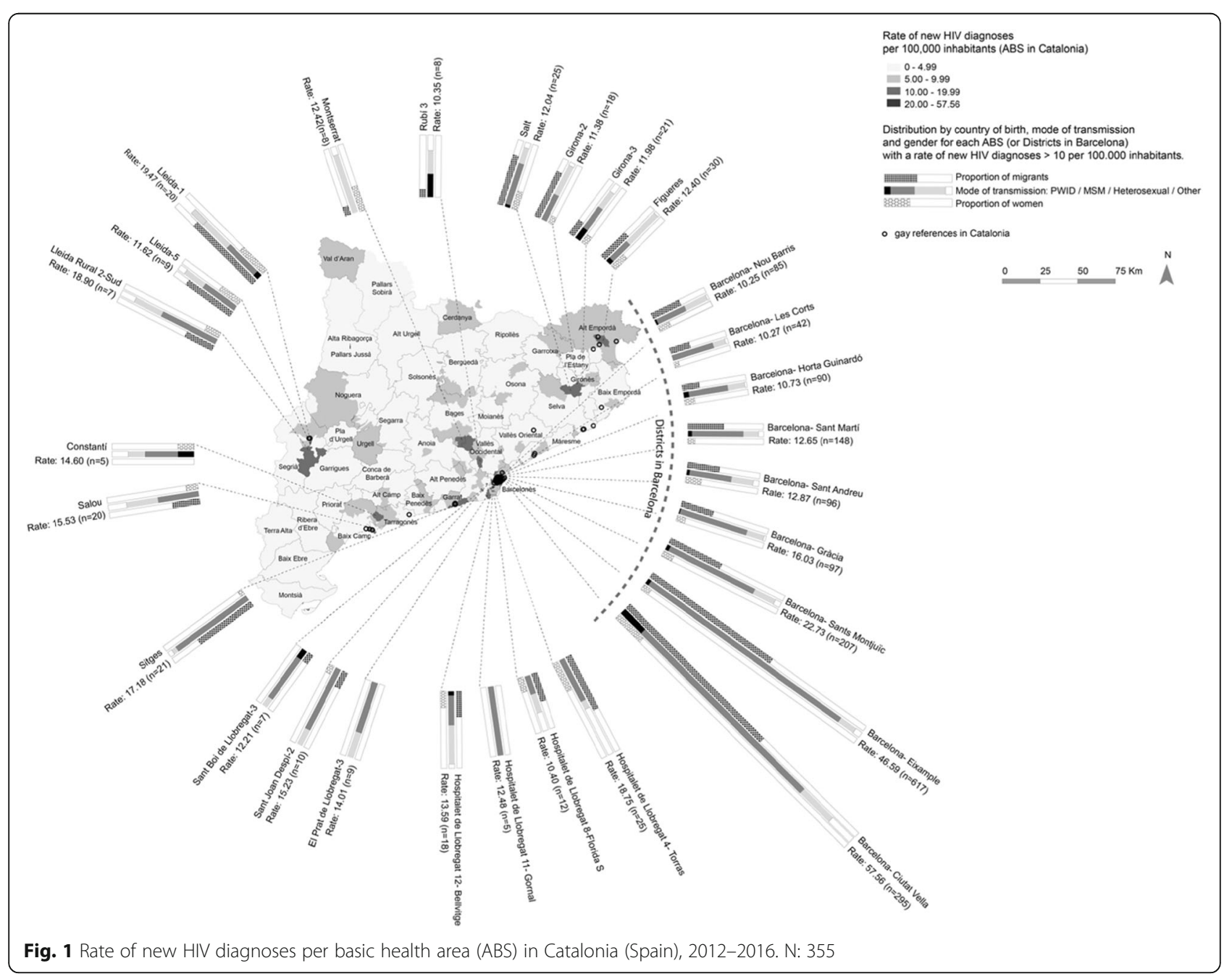


from being homogenously distributed across Catalonia, with a gradient ranging from rural low-incidence areas to urban high-incidence areas and the highest rates in the ABSs of Barcelona city and its metropolitan area. A total of 22 ABSs out of 355 had no HIV diagnoses during the study period, while 31 had only one case.

A marked gender difference was observed in the diagnosis rate (Fig. 1), with men being the most affected by the HIV epidemic in Catalonia. The main mode of transmission of HIV was GBMSM in the vast majority of ABSs, with a diagnosis rate $>10$ cases per 100,000 population. The percentage of new HIV diagnoses among the migrant population varied widely across Catalonia (Fig. 1).

The circles in the map of Figs. 1 and 2 show the gay locations. A zoom of Barcelona city and its metropolitan area is shown in Fig. 2. Both maps reveal a spatial association between the rate of new HIV diagnoses and the number of gay locations in the ABS. Gay locations were concentrated in downtown Barcelona city and in the village of Sitges. The ABS "Universitat" (Barcelona), which presented the highest rate, with 154.23 cases per 100,000 persons, was the ABS with most gay venues $(N=82)$ in Catalonia. The second ABS in number of gay references was Sitges $(N=40)$, with a new HIV diagnosis rate of 17.18 cases per 100,000 persons.

Mean new HIV diagnosis rates tended to increase in all cases, with the exception of the deprivation index, where the highest HIV diagnosis rate (11.6 cases per 100,000 persons) was found in the first quartile of less deprived ABS. The Pearson correlation with the diagnosis rate was positive and significant $(p<0.001)$ for all the

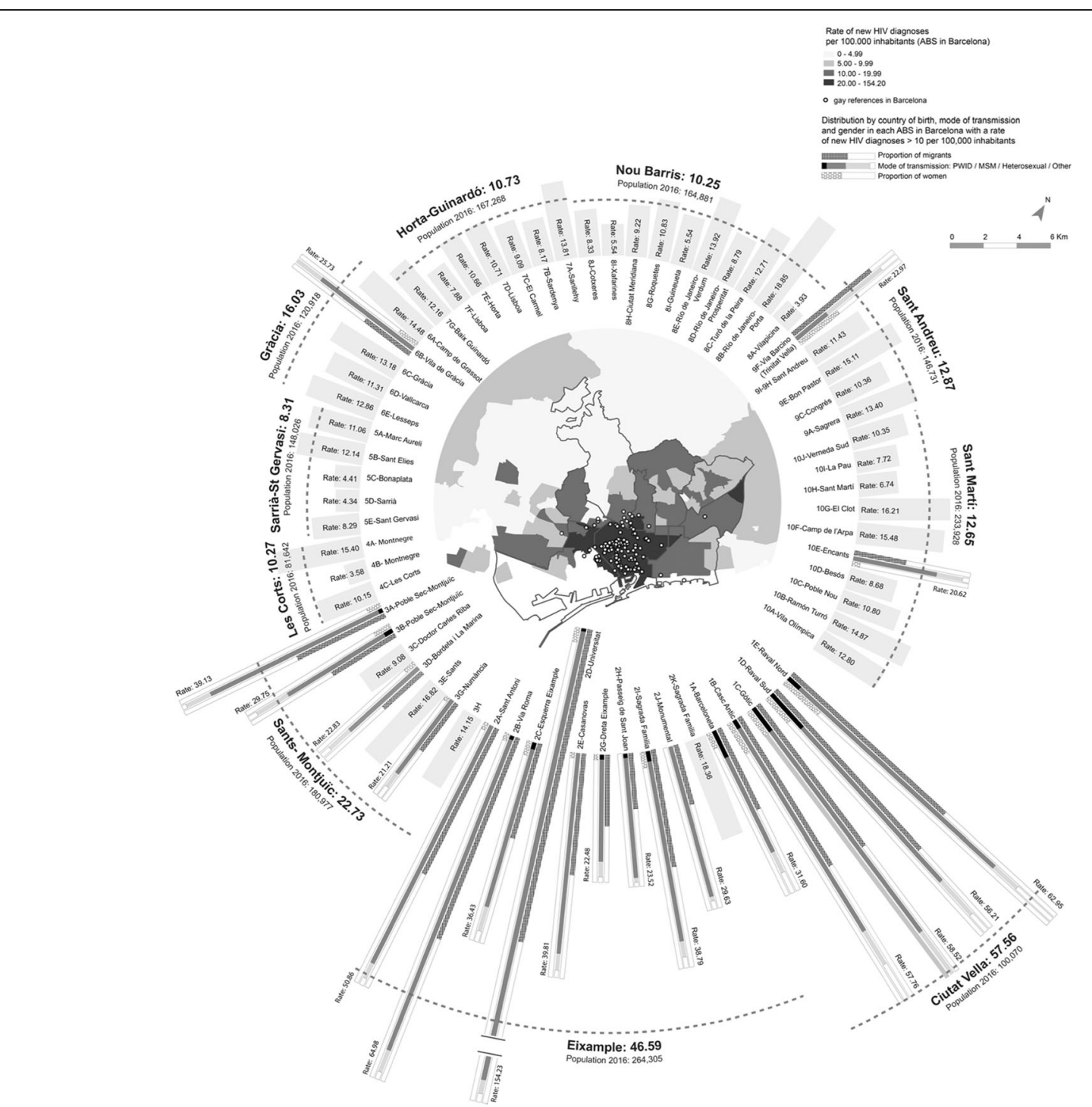

Fig. 2 Rate of new HIV diagnoses per basic health area (ABS) in Barcelona and its metropolitan area, Catalonia (Spain), 2012-2016 
Table 2 Mean rate of new HIV diagnoses in Catalonia basic health areas (ABS) for each quartile (2a) / category (2b) of the risk factor, 2012-2016. N: 355

\begin{tabular}{llllll}
\hline 2a) & \multicolumn{2}{l}{ Quartile } & & & Corr. $^{\text {b }}$ \\
& 1st & 2nd & 3rd & 4th & \\
Men, 15-44 years (\%) & 4.60 & 5.78 & 7.13 & 14.36 & $0.473^{* * *}$ \\
Men, Western Europe (\%) & 5.01 & 5.49 & 5.71 & 15.64 & $0.491^{* * *}$ \\
Men, Latin America (\%) & 3.90 & 4.74 & 6.70 & 16.52 & $0.318^{* * *}$ \\
Gay references (count) & 6.22 & 30.50 & 50.14 & 67.44 & $0.725^{\text {**** }}$ \\
Infection from GBMSM (\%) & 5.31 & 4.77 & 5.93 & 17.68 & $0.410^{* * *}$ \\
Deprivation index & 11.60 & 6.56 & 5.29 & 8.40 & $-0.129^{*}$ \\
2b) & & & & & \\
Type of municipality & (n) & & Corr. & & \\
Rural & 125 & 21.15 & $0.289^{* * *}$ & & \\
Semi-urban & 89 & 7.97 & & & \\
Urban (county) & 26 & 3.66 & & & \\
Urban (metropolitan) & 48 & 5.31 & & & \\
Urban (Barcelona) & 67 & 7.03 & & & \\
Total & 355 & 6.21 & & & \\
\hline
\end{tabular}

${ }^{a}$ Quantiles calculated at 95, 97.5 and $99.15 \%$ for this variable

bearson

'Eta-squared

"Significant at $p<0.05 ;{ }^{* *}$ Significant at $p<0.01$; ** Significant at $\mathrm{p}<0.001$ GBMSM: Gay, bisexual and other men who have sex with men

factors considered except for the deprivation index (Table 2a). The mean new diagnosis rate was clearly higher for the city of Barcelona than for the rest of Catalonia (21.16 cases per 100,000 population), and type of municipality was significantly associated with HIV diagnosis rate (eta-squared $=0.289, \mathrm{p}<0.001)$ (Table $2 \mathrm{~b}$ ).

The statistical modeling of new HIV diagnoses in Model (1) showed significant spatial autocorrelation (Moran I, 0.163, $\mathrm{p}<0.001$, see Table 3), suggesting the need for correction; therefore, only Model (2) results (including the autocovariate) are commented on. The McFadden $R^{2}$ value was 0.236 , indicating adequate goodness of fit of the model. The ABSs that proved to be significantly associated with a higher rate of new HIV diagnoses were those located in the city of Barcelona (IRR, 2.520; $P<0.001$ ), those with a higher proportion of men aged 15-44 years (IRR, 1.193; $P=0.003$ ), those with higher proportion of MSM as the transmission mode (IRR, 1.230; $P=0.030$ ), those with a higher proportion of men from Western Europe (IRR, 1.281; $\mathrm{P}=0.003$ ) and men from Latin America (IRR: $1.260 \mathrm{P}=0.003$ ), and those with a higher number of gay locations (IRR, 2.665; $\mathrm{P}<0.001$ ). On the contrary, no association was observed between HIV diagnosis rate and economic deprivation (Table 3).

\section{Discussion}

The main aim of this study was to identify socioeconomic risk factors associated with the rate of new diagnoses of HIV infection in Catalonia (Spain) and their spatial distribution. We performed an ecological study at the small area level based on surveillance data from the national registry of new diagnoses of HIV and publicly accessible data from the Agency of Health Quality and Evaluation of Catalonia and the Information System for the Development of Research in Primary Care. We also assessed the effect of the number of gay locations in the neighborhood.

Geographical information systems can help to better understand the spatial distribution of HIV and high-risk areas for disease transmission and acquisition [24, 25]. Our study showed the heterogeneous distribution of the rate of new diagnoses across Catalonia. Our data revealed differences for sex, transmission mode, and country of birth between small areas in Catalonia. The highest rates of new HIV diagnoses were in ABSs located in urban areas, especially the city of Barcelona. While differences between urban and rural areas have been reported [2], the fact that people living with HIV in rural areas are more likely to be diagnosed later than their urban counterparts [26, 27] should be taken into account. Rural residents at risk for or living with HIV experience barriers that include greater local stigma about HIV infection, a socially conservative climate, and scarcity of funding for widespread testing and treatment programs [3].

Our results indicate that a higher percentage of transmission via GBMSM in ABSs is associated with a higher incidence of HIV. This observation is consistent with the finding that GBMSM was the most common transmission mode in Catalonia during the study period, ranging from $53.7 \%$ of the new diagnoses of HIV infection reported among GBMSM in 2012 to $57.3 \%$ in 2016 [19]. We found that the HIV diagnosis rate was higher in ABSs with a higher number of gay locations. In Catalonia gay neighborhoods concentrate higher proportions of GBMSM than other areas of settings. Consequently, as GBMSM is the group most affected by the HIV epidemic in Catalonia, we can expect to find higher rates of new diagnoses in these neighborhoods. The probability of acquiring the infection by having HIV-positive people among one's own sexual contacts is higher for people living in areas with a high prevalence of HIV. On the other hand, GBMSM living in gay neighborhoods often engage in the gay fastlane subculture (defined as a way of life that is full of excitement, activity, and often risk), where drug use is frequently perceived to be normative [28]. Previous studies associated living in a gay neighborhood with the use of drugs to enhance sexual experiences and recent unprotected anal intercourse [11, 13]. Thus, the neighborhood itself could shape riskier sexual behavior through social networks and social norms. 
Table 3 Factors associated with the rate of new HIV diagnoses in basic health areas (ABS) of Catalonia (Spain), 2012-2016. N: 355

\begin{tabular}{|c|c|c|c|c|c|c|c|}
\hline & \multicolumn{2}{|c|}{ MODEL (1) } & & \multirow[b]{3}{*}{$\operatorname{Pr}(>|z|)$} & \multicolumn{2}{|c|}{ MODEL (2) } & \multirow[b]{3}{*}{$\operatorname{Pr}(>|z|)$} \\
\hline & \multicolumn{2}{|c|}{ Negative Binomial } & & & \multicolumn{2}{|c|}{ Model (1) + Autocovariate } & \\
\hline & Coef. & $(95 \% \mathrm{Cl})$ & & & Coef. & $(95 \% \mathrm{Cl})$ & \\
\hline \multicolumn{8}{|l|}{ Variable (ABS level) } \\
\hline Constant & 0 & $(0-0)$ & 0 & $<0.001$ & 0 & $(0-0)$ & $<0,001$ \\
\hline \multicolumn{8}{|l|}{ Type of municipality } \\
\hline Rural & Ref. & & & & Ref. & & \\
\hline Semi-urban & 1.147 & $(0.962-1.369)$ & & 0,126 & 1.118 & $(0.941-1.329)$ & 0,204 \\
\hline Urban (county) & 1.586 & $(1.231-2.043)$ & & $<0.001 * * *$ & 1.44 & $(1.122-1.849)$ & $0,004 * *$ \\
\hline Urban (metropolitan) & 1.331 & $(1.063-1.669)$ & & $0,012 *$ & 1.307 & $(1.048-1.630)$ & $0,016 *$ \\
\hline Urban (Barcelona) & 2.52 & $(2.020-3.149)$ & & $<0.001 * * *$ & 2.483 & $(2.004-3.080)$ & $<0.001 * * *$ \\
\hline Men, $15-44$ years (\%) & 1.193 & $(1.113-1.280)$ & & $<0.001 * * *$ & 1.189 & $(1.112-1.272)$ & $<0.001^{* * *}$ \\
\hline \multicolumn{8}{|l|}{ Men, Western Europe (\%) ${ }^{a}$} \\
\hline$[0.02-2.13]$ & Ref. & & & & & & \\
\hline$[2.13-13.2]$ & 1.281 & $(1.085-1.513)$ & & $0,003 * *$ & 1.29 & $(1.098-1.516)$ & $0,002 * *$ \\
\hline \multicolumn{8}{|l|}{ Men, Latin America (\%) } \\
\hline$[0.45-5.35]$ & Ref. & & & & & & \\
\hline$[5.35-22.2]$ & 1.26 & $(1.077-1.473)$ & & $0,003 * *$ & 1.246 & $(1.071-1.449)$ & $0,004 * *$ \\
\hline \multicolumn{8}{|l|}{ Gay references (count) } \\
\hline$[0-2]$ & Ref. & & & & & & \\
\hline [3-6] & 1.342 & $(0.995-1.824)$ & & 0,056 & 1.343 & $(1.009-1.799)$ & 0,044 \\
\hline$[7-82]$ & 2.665 & $(1.924-3.742)$ & & $<0.001 * * *$ & 2.529 & $(1.853-3.491)$ & $<0.001^{* * *}$ \\
\hline \multicolumn{8}{|l|}{ Infection from MSM (\%) } \\
\hline$[0.72-45.4]$ & Ref. & & & & Ref. & & \\
\hline$(45.4-55.6]$ & 0.878 & $(0.733-1.052)$ & & 0,158 & 0.887 & $(0.744-1.057)$ & 0,181 \\
\hline$[55.6-67.1]$ & 1.024 & $(0.865-1.212)$ & & 0,779 & 1.027 & $(0.871-1.210)$ & 0,751 \\
\hline$[67.1-95.2]$ & 1.23 & $(1.016-1.488)$ & & $0,03 *$ & 1.226 & $(1.019-1.475)$ & 0,028 * \\
\hline \multicolumn{8}{|l|}{ Deprivation index ${ }^{b}$} \\
\hline$[0.00-37.4]$ & Ref. & & & & Ref. & & \\
\hline$[37.4-46.4]$ & 1.031 & $(0.859-1.237)$ & & 0,745 & 1.004 & $(0.842-1.198)$ & 0,965 \\
\hline$[46.4-54.5]$ & 1.045 & $(0.865-1.264)$ & & 0,647 & 1.009 & $(0.838-1.214)$ & 0,926 \\
\hline$[54.5-100.0]$ & 1.131 & $(0.923-1.387)$ & & 0,237 & 1.092 & $(0.896-1.332)$ & 0,382 \\
\hline Autocovariate & - & - & & - & 1.156 & $(1.09-1.227)$ & $<0.001^{* * *}$ \\
\hline \multicolumn{8}{|l|}{ Model adjustment } \\
\hline McFadden's R2 & 0.226 & & & & 0.236 & & \\
\hline$-2 \mathrm{LL}$ & -1789.8 & & & & -1767.4 & & \\
\hline $\mathrm{AIC}$ & 1823.8 & & & & 1803.4 & & \\
\hline $\mathrm{BIC}$ & 1889.6 & & & & 1873.1 & & \\
\hline$n$ & 355 & & & & 355 & & \\
\hline g.l. & 339 & & & & 338 & & \\
\hline Moran I test & 0.163 & 0,033 & & $<0.001$ & -0.038 & 0,033 & 0,841 \\
\hline
\end{tabular}


The rate of new diagnoses of HIV infection is higher in ABS with a higher proportion of migrants from Western Europe and Latin America. Transmission of HIV has been severely affected by mobility. Migrants are considered a key group at risk for HIV infection [6], and the European Centre for Disease Prevention and Control (ECDC) and the European Commission consider them a priority group in HIV prevention and care [29]. In Catalonia, sex between men is the most frequent route of transmission among migrants from Western Europe (65\%) and from Latin America (60.4\%), who account for 19.8 and $70.5 \%$, respectively, of all cases of HIV infection reported among migrant GBMSM [30] in Catalonia. The mode of transmission of HIV infection among migrants in Western Europe mimics epidemics in their countries of origin, that is, mainly through GBMSM. Conversely, transmission of HIV infection between men is less common in Latin America, and the high rates of HIV infection among GBMSM from Latin America may reflect selective migration of GBMSM from this region to Europe owing to the more permissive attitudes toward same sex relationships [7].

No association was observed between the socioeconomic deprivation index and the new HIV diagnosis rate. Other factors shown to be associated with the incidence of HIV infection among heterosexual men and women and people who inject drugs include high income inequality, low income, high unemployment, and high poverty, although these are not significantly associated with incidence among GBMSM [18]. Economic deprivation is not thought to be a significant factor, since the HIV epidemic in Catalonia is associated mainly with GBMSM. Previous studies have reported higher incomes among GBMSM residing in gay neighborhoods than in those who do not [31]. Generally, urban areas with a high significance for the gay community confirm the paradox of the post-Fordist city, i.e., ghettos develop in the city, although not all are marginal and some, for example, gay neighborhoods, show signs of urban elitization [32].

Our study has several limitations. Given that we report the results of an ecological study at the ABS level, the inferences drawn are only valid at this level and do not demonstrate any causal relationship. Furthermore, our results are based on the place of residence of newly diagnosed persons. However, place of residence and place of exposure may not necessarily be the same. Data on the rate of new diagnoses were obtained from the Catalan HIV Surveillance Registry, where $10-20 \%$ of cases are thought to be undiagnosed, as reported in similar registries [33]. The percentage of transmission among GBMSM is estimated from very small samples in many ABSs. In addition, no information was available on the mode of transmission in $9 \%$ of all diagnoses.
Nevertheless, it is important to remember that we used population-based sources of data on new HIV diagnoses and publicly available socioeconomic data. We complemented the results of the multivariate analysis to describe the distribution of new HIV diagnoses with geovisual representations using ring maps. Another strength of the study is the use of the ABS-the smallest administrative territorial health unit in Catalonia-as a geographical study unit. This approach could potentially facilitate future management of the HIV epidemic.

\section{Conclusions}

Our results confirm the epidemiological pattern of the HIV epidemic observed in Catalonia. Nevertheless, the spatial analysis we performed provided us with a very accurate picture of the heterogeneous distribution of new diagnoses in Catalonia. We also determined factors related to $\mathrm{ABS}$ with a higher rate of new diagnoses. Our findings have important implications for the implementation of a scientific and public health response to HIV/ AIDS. We showed that socioeconomic deprivation is not related to the incidence of HIV infection, thus indicating that the high rate of newly diagnosed HIV infection in certain small areas suggests that the socioeconomic level should not be the only criterion for budgetary allocation in the ABS. Furthermore, HIV prevention programs in Catalonia should continue to focus on GBMSM, mainly in urban areas. Our study identified geographical hotspots for HIV and could help guide the locations where HIV testing should be enhanced in primary care and where to implement specific HIV prevention campaigns.

\section{Abbreviations}

ABS: Basic health area; AIDS: Acquired immune deficiency syndrome; GBMSM: Gay, bisexual and other men who have sex with men; HIV: Human immunodeficiency virus; IRR: Incidence rate ratios; PWID: People who inject drugs

\section{Acknowledgements \\ The authors thank the Heath Department of the Catalan Government (Spain) and Thomas O'Boyle for reviewing the English. Joan Benach gratefully acknowledges the financial support by ICREA under the ICREA Acadèmia programme.}

\section{Authors' contributions \\ CA conceived of the original idea, lead the research and wrote the manuscript with input from all of the authors. NF participated in the study design and made the ring maps. FB performed the statistical analysis and contributed to the writing of the manuscript. MJ and JP contributed to the study design and the interpretation of the results. NV and AM extracted and managed the data from the Catalan HIV Surveillance Registry and participated in the study design. JB and JC supervised the study, participated in the study design and contributed to the interpretation of the results. All authors discussed the results and commented on the manuscript. The authors read and approved the final manuscript.}




\section{Availability of data and materials}

Data is publically available on demand by contacting the correspondence author: Cristina Agustí, cagusti@iconcologia.net.

\section{Ethics approval and consent to participate}

The authors declare that the study was approved by the Ethics Committee of the Hospital Germans Trias i Pujol (Badalona, Spain).

\section{Consent for publication}

Not applicable.

\section{Competing interests}

CA and JC had received Financial support for research and travel reimbursements from Gilead Sciences and ViiV Healthcare. The other authors declare that they not have competing interests.

\section{Author details}

'Centre d'Estudis Epidemiològics sobre les Infeccions de Transmissió Sexual i Sida de Catalunya (CEEISCAT), Agència de Salut Pública de Catalunya (ASPC), Generalitat de Catalunya, Edifici Muntanya, Ctra Can Ruti, Cami de les Escoles s/n, 08916 Badalona, Barcelona, Spain. ${ }^{2}$ Centro de Investigación Biomédica en Red de Epidemiologia y Salud Pública CIBERESP, Madrid, Spain. ${ }^{3}$ Fundació Institut d'Investigació Germans Trias i Pujol IGTP, Badalona, Barcelona, Spain. ${ }^{4}$ Department of Geography, Universitat de Barcelona, Barcelona, Spain. ${ }^{5}$ Department of Political and Social Sciences, Health Inequalities Research Group, Employment Conditions Knowledge Network (GREDS-EMCONET), Universitat Pompeu Fabra, Barcelona, Spain. ${ }^{6} J o h n s ~ H o p k i n s$ University-Universitat Pompeu Fabra Public Policy Center, Barcelona, Spain. 7 Unit of Infections and Cancer - Information and Interventions (UNIC - I\&I), Cancer Epidemiology Research Program (CERP), Hospitalet de Llobregat, Barcelona, Spain. ${ }^{8}$ Cancer Screening Unit, Catalan Institute of Oncology, Hospitalet de Llobregat, Barcelona, Spain. 'Vall d'Hebron Institute for Research (VHIR), Barcelona, Spain. ${ }^{10}$ Infectious Disease Department, Hospital Clínic de Barcelona, Barcelona, Spain. ${ }^{11}$ Departament de Pediatria, d'Obstetrícia i Ginecologia i de Medicina Preventiva i de Salut Pública, Universidad Autónoma de Barcelona, Bellaterra, Cerdanyola del Vallès, Barcelona, Spain. ${ }^{12}$ Grupo de Investigación Transdisciplinar sobre Transiciones Socioecológicas (GinTRANS2), Universidad Autónoma de Madrid, Madrid, Spain

Received: 29 May 2020 Accepted: 23 September 2020

Published online: 09 October 2020

\section{References}

1. World Health Organization. MONITORING An essential step for achieving health equity [Internet]. Geneva; Available from: http://www.who.int/gho/ health_equity/en/. Accessed 6 Oct 2020.

2. Patel D, Taylor-Aidoo N, Marandet A, Heitgerd J, Maciak B. Assessing Differences in CDC-Funded HIV Testing by Urbanicity, United States, 2016. J Community Health. 2019;44(1):95-102 Available from: http://www.ncbi.nlm. nih.gov/pubmed/30069826. [cited 2019 Jul 1].

3. Schafer KR, Albrecht H, Dillingham R, Hogg RS, Jaworsky D, Kasper K, et al. The Continuum of HIV Care in Rural Communities in the United States and Canada. JAIDS J Acquir Immune Defic Syndr. 2017;75(1):35-44 Available from: http://insights.ovid.com/crossref?an=00126334-201705010-00006. [cited 2019 Jul 1].

4. Ohl ME, Perencevich E. Frequency of human immunodeficiency virus (HIV) testing in urban vs. rural areas of the United States: Results from a nationally-representative sample. BMC Public Health. 2011;11(1):681 Available from: http://www.ncbi.n/m.nih.gov/pubmed/21884599. [cited 2019 Jul 1].

5. Deane KD, Parkhurst JO, Johnston D. Linking migration, mobility and HIV. Trop Med Int Health. 2010;15(12):1458-63 Available from: http://doi.wiley. com/10.1111/j.1365-3156.2010.02647.x. [cited 2019 Jul 1]

6. Camlin CS, Charlebois ED. Mobility and its Effects on HIV Acquisition and Treatment Engagement: Recent Theoretical and Empirical Advances. Curr HIV/AIDS Rep. 2019; Available from: http://www.ncbi.nlm.nih.gov/ pubmed/31256348. [cited 2019 Jul 1].

7. Hernando V, Alvárez-del Arco D, Alejos B, Monge S, Amato-Gauci AJ, Noori $T$, et al. HIV Infection in Migrant Populations in the European Union and European Economic Area in 2007-2012. JAIDS J Acquir Immune Defic
Syndr. 2015;70(2):204-11 Available from: http://www.ncbi.n/m.nih.gov/ pubmed/26068723. [cited 2019 Jul 1].

8. Roux AVD. Investigating neighborhood and Area effects on health. Am J Public Health. 2001;91(11):1783-9.

9. Tieu HV, Koblin BA, Latkin C, Curriero FC, Greene ER, Rundle A, et al. Neighborhood and network characteristics and the HIV Care continuum among gay, bisexual, and other men who have sex with men. J Urban Heal. 2018:1-17. https://doi.org/10.1007/s11524-018-0266-2.

10. Baral S, Logie CH, Grosso A, Wirtz AL, Beyrer C. Modified social ecological model: a tool to guide the assessment of the risks and risk contexts of HIV epidemics. BMC Public Health. 2013;13(1):1 Available from: BMC Public Health.

11. Buttram ME, Kurtz SP. Risk and protective factors associated with gay neighborhood Residence. Am J Mens Health. 2013;7(2):110-8.

12. Bauermeister JA, Connochie D, Eaton L, Demers M, Stephenson R Geospatial indicators of space and place: a review of multilevel studies of HIV prevention and Care outcomes among young men who have sex with men in the United States. J Sex Res. 2017;54(4-5):446-64.

13. Kelly BC, Carpiano RM, Easterbrook A, Parsons JT. Sex and the community: the implications of neighbourhoods and social networks for sexual risk behaviours among urban gay men. Sociol Heal IIIn. 2012;34(7):1085-102.

14. Harling G, Subramanian SV, Bärnighausen T, Kawachi I. Income inequality and sexually transmitted in the United States: Who bears the burden? Soc Sci Med. 2014;102:174-82. https://doi.org/10.1016/j.socscimed.2013.11.025.

15. Lòpez-De Fede A, Stewart JE, Hardin JW, Mayfield-Smith K, Sudduth D. Spatial visualization of multivariate datasets: an analysis of STD and HIV/ AIDS diagnosis rates and socioeconomic context using ring maps. Public Health Rep. 126 Suppl 3:115-26 Available from: http://www.ncbi.nlm.nih. gov/pubmed/21836744. [cited 2019 Apr 17].

16. Krieger N, Waterman PD, Chen JT, Soobader M-J, Subramanian S. Monitoring socioeconomic inequalities in sexually transmitted infections, tuberculosis, and violence: geocoding and choice of Area-based socioeconomic measures - the public health disparities geocoding project (US). Public Health Rep. 2003;118(3):240-60.

17. Hughes GJ, Gorton R. Inequalities in the incidence of infectious disease in the north east of England: a population-based study. Epidemiol Infect. 2015; 143(1):189-201.

18. Buot MLG, Docena JP, Ratemo BK, Bittner MJ, Burlew JT, Nuritdinov AR, et al Beyond race and place: distal sociological determinants of HIV disparities. PLoS One. 2014;9(4):e91711.

19. Centre d'Estudis Epidemiològics sobre les Infeccions de Transmissió Sexual i Sida de Catalunya (CEEISCAT). Vigilància epidemiològica de la infecció pel VIH i la SIDA a Catalunya. Informe anual 2017. Badalona; 2018.

20. European Centre for Disease Prevention and Control/WHO Regional Office for Europe. HIV/AIDS surveillance in Europe 2017 - 2016 data. Stockholm: ECDC; 2017.

21. Agresti A, Coull BA. Approximate is better than "exact" for interval estimation of binomial proportions. Am Stat. 1998:52(2):119-26.

22. García-Altés A, Ruiz-Muñoz D, Colls C, Mias M, Martín Bassols N. Socioeconomic inequalities in health and the use of healthcare services in Catalonia: analysis of the individual data of 7.5 million residents. J Epidemiol Community Health. 2018;72(10):871-9. https://doi.org/10.1136/jech-2018210817.

23. Huang G, Govoni S, Choi J, Hartley D, Wilson J. Geovisualizing data with ring maps. ArcUser, Winter. 2008:54-55. http://www.esri.com/news/arcuser/ 0408/files/ringmaps.pdf.

24. Stopka TJ, Brinkley-Rubinstein L, Johnson K, Chan PA, Hutcheson M, Crosby R, et al. HIV clustering in Mississippi: spatial epidemiological study to inform implementation science in the deep south. JMIR Public Health Surveill. 2018;4(2):e35.

25. Stopka TJ, Lutnick A, Wenger LD, DeRiemer K, Geraghty EM, Kral AH. Demographic, risk, and spatial factors associated with over-the-counter syringe purchase among injection drug users. Am J Epidemiol. 2012;176(1): 14-23.

26. Trepka MJ, Fennie KP, Sheehan DM, Lutfi K, Maddox L, Lieb S. Late HIV Diagnosis: Differences by Rural/Urban Residence, Florida, 2007-2011. AIDS Patient Care STDS. 2014:28(4):188-97 Available from: http://www.ncbi.nlm. nih.gov/pubmed/24660767. [cited 2019 Jul 11].

27. Hall HI, Tang T, Espinoza L. Late Diagnosis of HIV Infection in Metropolitan Areas of the United States and Puerto Rico. AIDS Behav. 2016;20(5):967-72 Available from: http://www.ncbi.nlm.nih.gov/pubmed/26542730. [cited 2019 Jul 11]. 
28. Kurtz SP. In: Cohler B, editor. The story of sexual identy: Narrative perspectives on the gay and lesbian life course. New York: Oxford Uni. Hammack, PL; 2009. p. 157-75.

29. European Centre for Disease Prevention and Control (ECDC). Assessing the burden of key infectious diseases affecting migrant populations in the EU/ EEA. Stockholm: European Centre for Disease Prevention and Control; 2014. https://doi.org/10.2900/28792.2014.

30. Reyes-Urueña J, Campbell C, Hernando C, Vives N, Folch C, Ferrer L, et al. Differences between migrants and Spanish-born population through the HIV care cascade, Catalonia: an analysis using multiple data sources. Epidemiol Infect. 2017;145(8):1670-81 Available from: https://www. cambridge.org/core/product/identifier/S0950268817000437/type/journal_ article. [cited 2019 Jul 1].

31. Mills TC, Stall R, Pollack L, Paul JP, Binson D, Canchola J, et al. Health-related characteristics of men who have sex with men: a comparison of those living in "gay ghettos" with those living elsewhere. Am J Public Health. 2001:91(6):980-3.

32. Salinas VF. Visibilidad y escena gay masculina en la ciudad española. Doc d'Analisi Geogr. 2007;49:139-60.

33. Mammone A, Pezzotti P, Regine V, Camoni L, Puro V, Ippolito G, et al. How many people are living with undiagnosed HIV infection? An estimate for Italy, based on surveillance data. AIDS. 2016;30(7):1131-6 Available from: http://www.ncbi.nlm.nih.gov/pubmed/26807973. [cited 2019 Jul 5].

\section{Publisher's Note}

Springer Nature remains neutral with regard to jurisdictional claims in published maps and institutional affiliations.

Ready to submit your research? Choose BMC and benefit from:

- fast, convenient online submission

- thorough peer review by experienced researchers in your field

- rapid publication on acceptance

- support for research data, including large and complex data types

- gold Open Access which fosters wider collaboration and increased citations

- maximum visibility for your research: over $100 \mathrm{M}$ website views per year

At $\mathrm{BMC}$, research is always in progress.

Learn more biomedcentral.com/submissions 